\title{
Application of a surgical nursing cooperation program in laparoscopic pancreaticoduodenectomy
}

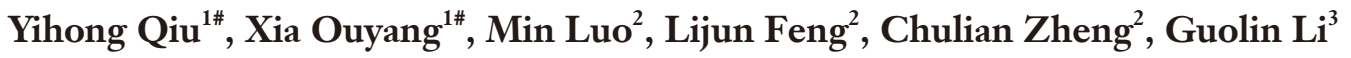 \\ ${ }^{1}$ Department of Nursing, Sun Yat-sen Memorial Hospital, Guangzhou, China; ${ }^{2}$ Operating Room, Sun Yat-sen Memorial Hospital, Guangzhou, \\ China; ${ }^{3}$ Department of Hepatopancreatobiliary Surgery, Sun Yat-sen Memorial Hospital, Guangzhou, China \\ Contributions: (I) Conception and design: Y Qiu, X Ouyang, G Li; (II) Administrative support: X Ouyang, G Li; (III) Provision of study materials or \\ patients: G Li; (IV) Collection and assembly of data: X Ouyang, L Min, L Feng, C Zheng; (V) Data analysis and interpretation: Y Qiu, L Min, L \\ Feng, G Li; (VI) Manuscript writing: All authors; (VII) Final approval of manuscript: All authors. \\ "These authors contributed equally to this work. \\ Correspondence to: Guolin Li. Department of Hepatopancreatobiliary Surgery, Sun Yat-sen Memorial Hospital, Guangzhou, China. \\ Email: liglin@mail.sysu.edu.cn.
}

Background: To evaluate the value of programmed surgical nursing in laparoscopic pancreaticoduodenectomy (LPD) and summarize the experience.

Methods: The clinical data of 80 patients who received LPD in Sun Yat-sen Memorial Hospital from January 2017 to December 2018 were analyzed retrospectively. A total of 40 patients were treated with traditional surgical nursing as the control group in the earlier stage. Afterwards, another 40 cases in the experimental group were treated using the surgical nursing program. Operation time, blood loss, and satisfaction of surgeons were analyzed.

Results: In all, 80 cases were successfully completed, and no significant difference was observed in the preoperative data statistics between these two groups $(\mathrm{P}>0.05)$. Compared with the control group, the average operation time and the average blood loss of the experimental group were significantly reduced (288.9 \pm 11.14 vs. $364.5 \pm 10.84 \mathrm{~min}, \mathrm{P}<0.05 ; 135.3 \pm 20.12$ vs. $364.8 \pm 77.39 \mathrm{~mL}, \mathrm{P}<0.05)$, and the satisfaction of surgeons was significantly higher $(95 \%$ vs. $80 \%, \mathrm{P}<0.05)$.

Conclusions: Skilled execution of nursing cooperation is crucial in LPD. Through appropriate preoperative preparation, gaining mastery operation steps, remaining in sync with surgeons, and perfecting the management details, the surgical nursing cooperation program can improve the satisfaction of the surgeons and make operations more efficient.

Keywords: Laparoscopic surgery; pancreaticoduodenectomy; programmed process; nursing coordination

Submitted Aug 10, 2020. Accepted for publication Oct 09, 2020.

doi: 10.21037 /gs-20-726

View this article at: http://dx.doi.org/10.21037/gs-20-726

\section{Introduction}

Because of the complexity digestive tract reconstruction and the long operation time and high rate of laparotomy transition, the safety and feasibility of laparoscopic pancreaticoduodenectomy (LPD) have been widely disputed. This technology has remained controversial since it was first reported in 1994 (1). However, with the recent update in equipment and the accumulation of surgical experience, this method has significantly matured.
In recent years, the cases of LPD performed in China had increased explosively, and a number of literatures have made detailed studies on the safety and feasibility of LPD $(2,3)$. We are one of the earliest centers to perform laparoscopic pancreaticoduodenectomy in China. Our surgical team had gained rich clinical experience in total laparoscopic pancreaticoduodenectomy and digestive tract reconstruction, and gradually formed a characteristics procedural and standardized surgical procedure. However, 
the operation procedure of total LPD is still complicated, and accidental bleeding still may occur during the operation (4), and skilled cooperation is critical for LPD (5). We developed a surgical nursing cooperation program in order to reduce the intraoperative complications of LPD and increase satisfaction of surgeons.

We present the following article in accordance with the STROBE reporting checklist (available at http://dx.doi. org/10.21037/gs-20-726).

\section{Methods}

\section{General data}

The clinical data of 80 patients who received LPD in Sun Yat-sen Memorial Hospital from January 2017 to December 2018 were analyzed retrospectively. Among these patients, 40 were treated with traditional surgical nursing as the control group in the earlier stage. Following this, another 40 cases in the experimental group were treated using the surgical nursing program. Gender, age, and other general data were collected.

All procedures performed in this study involving human participants were in accordance with the Declaration of Helsinki (as revised in 2013). Individual consent for this retrospective analysis was waived. This study was also approved by Medical Ethics Committee of Sun Yat-sen Memorial Hospital, Sun Yat-sen University (No.SYSECKY-KS-2020-144).

\section{Surgical methods}

A 12-mm laparoscopic puncture cannula needle was used in the 5-hole method to establish operating channels. Afterwards, the surgeons checked the abdominal cavity, lifted the left side of the liver and hepatic ligament, transected the stomach, and dissected the superior pancreatic margin. The common hepatic artery and gastroduodenal artery were treated in turn, and then portal vein was appeared. The inferior pancreatic margin was dissected to open the posterior pancreatic tunnel and to separate the pancreas. Kocher incision was used to fully dissociate the duodenum and separate the jejunum. The pancreatic uncinate process was separated from the superior intestinal blood vessel along the superior mesenteric artery. Then, cholecystectomy was performed, and the bile duct was separated. At last, digestive tract reconstruction was carried out according to the Child method, a double cavity drainage tube was placed, and the incision was closed (5).

\section{Nursing methods}

In the control group, the nurses performed routine nursing methods, including preoperative instrument preparation, and cooperated according to the surgeon's instructions during the operation.

All nurses were required to undergo training for the operation and take a qualifying examination before being enrolled in the experimental group. They adopted the method of the nursing cooperation program, the details of which are described below.

(I) Preoperative preparation. The preoperative operation nursing team participates in the preoperative discussion of the patients, understands the basic situation of the patients, along with the location, occupation, blood vessels, and surrounding tissues and organs relevant to the procedure. The appropriate surgical items and equipment are then prepared individually. Additionally, nurses visit patients and describe the successful cases of the operation to strengthen the confidence of the patients.

(II) Management of surgical instruments. LPD requires a large number of surgical instruments and pipelines in the operation area, with the rational distribution of pipelines and the management of instruments being especially important. For this step, nurses should place all the pipelines before the surgeons. The main surgeon usually stands on the right side of the patient, and so all pipelines are arranged on the right side of the patient to facilitate the operation of the main surgeon. A saddle cloth bag designed by our department for placing ultrasonic knives, ligation bundles, and bipolar electrocoagulators is arranged on the patient's chest area and right thigh. All surgical instruments are classified and placed well to keep the operating table neat and to prevent any equipment from falling. The nurse stand on the same side as the surgeon. It is also a critical to ensure that surgeons and nurses remain in sync.

(III) Active cooperation with surgery. The anatomical structure of the LPD surgical area is complex and susceptible to unpredictable vascular variations. Nurses should act as the main assistant, and when the surgeon removes the equipment from the casing 
Table 1 Comparison of preoperative clinical data of laparoscopic pancreaticoduodenectomy

\begin{tabular}{lccc}
\hline Group & No. of cases & Gender (male/female) & Age (years) \\
\hline Control group & 40 & $27 / 13$ & $58.28 \pm 2.311$ \\
Experimental group & 40 & $25 / 15$ & $56.4 \pm 1.698$ \\
P values & & 0.220 & 0.5151 \\
\hline
\end{tabular}

passage, the nurses should help to fix the casing. Nurses should prepare the equipment to be used in the following step, and replace the equipment from the endoscopic passage to the abdominal cavity. The passing of equipment requires accuracy.

(IV) Classification of suture and ribbon lengths. The nurse measures the length of the suture and vascular ribbon with a sterile measuring ruler, and the length of the suture is standardized according to the site of the suture. The uniform length of the vascular pull ribbon used to separate the lifting vessels is $7 \mathrm{~cm}$, the suture for ligation and hemostasis is $15 \mathrm{~cm}$, and the suture for tissue suture is $20 \mathrm{~cm}$. These measurements are used to avoid the suture winding in the body cavity, and save time in the operation.

(V) Standardized placement of surgical equipment. A 3D laparoscopic system is conventionally used for this procedure, with the main screen placed on the right side of the patient's head and another display placed on the left side. The position of the instrument is placed to avoid obscuring the anesthetist's view, and to ensure that the surgeon's field of vision is consistent.

(VI) Dynamic adjustment of patient position to ensure surgical safety. All patients treated using this program are recumbent with the lower limbs separated by $40-50^{\circ}$ when the operation begins, in order to avoid excessive abduction and injury to the adductor muscle. After the establishment of the operation channel, the head of the bed is raised to $30-45^{\circ}$, so that the intestinal tube can slide naturally under the action of gravity to expose the operation field. When the pancreas hook process is freed, the head of the bed is raised and tilted $15-30^{\circ}$ to the left at the same time, which aids in exposing the pancreatic head (6). Both lower limbs and trunk are fixed with restraint bands, and the trunk restraint band is fixed with a cotton pad at the iliac joint to ensure the safety of surgery.
(VII) Integrated nursing intervention to prevent hypothermia during operation. A stable temperature of $23-24{ }^{\circ} \mathrm{C}$ is maintained (7), with a $37^{\circ} \mathrm{C}$ flushing fluid used to wash the abdominal cavity. $\mathrm{A} \mathrm{CO}_{2}$ heated pneumoperitoneum is used to adjust the temperature of the blanket according to the patient's temperature changes (8), which are monitored throughout the operation, with heat preservation measures being taken to maintain a stable temperature.

\section{Observation targets}

The operation time, blood loss, and surgeon satisfaction of the two groups were compared. A satisfaction score was obtained by querying the doctor's satisfaction with the cooperation during surgery, which was classified as follows: very satisfied, satisfied, and dissatisfied. The final satisfaction score was calculated as follows: (the total number of very satisfied + satisfied)/the total number of cases $\times 100 \%$.

\section{Statistical analysis}

Statistical analysis was performed using SPSS 20 software. Continuous variables are expressed as mean \pm standard deviation $(\bar{x} \pm s)$ and categorical variables are expressed as the number of cases and percentage. A $t$-test was used to compare the operation time and blood loss, while a Chisquare test was used to compare satisfaction. A $\mathrm{P}$ value $<0.05$ was considered to be statistically significant.

\section{Results}

No significant difference in the patients gender and age was observed between the two groups (Table 1).

The mean operative time of the experimental group was significantly reduced $(288.9 \pm 11.14$ vs. $364.5 \pm 10.84 \mathrm{~min}$, $\mathrm{P}<0.05)$, and the mean blood loss was significantly reduced $(135.3 \pm 20.12$ vs. $364.8 \pm 77.39 \mathrm{~mL}, \mathrm{P}<0.05)$ (Table 2).

For surgeon satisfaction, there were 18 very satisfactory, 
Table 2 Comparison of intraoperative data of laparoscopic pancreaticoduodenectomy

\begin{tabular}{lccc}
\hline Group & No. of cases & Operation time $(\mathrm{min})$ & Blood loss $(\mathrm{mL})$ \\
\hline Control group & 40 & $364.5 \pm 10.84$ & $364.8 \pm 77.39$ \\
Experimental group & 40 & $288.9 \pm 11.14$ & $135.3 \pm 20.12$ \\
P values & & $<0.0001$ & 0.0053 \\
\hline
\end{tabular}

14 satisfactory, and 8 unsatisfactory ratings in the control group, for a final rating of $80 \%$. There were 22 very satisfactory, 16 satisfactory, and 2 unsatisfactory ratings in the experimental group, for a final rating of $95 \%$. The difference was statistically significant $\left(\chi^{2}=5.618, P=0.007\right)$.

\section{Discussion}

The implementation of the procedure cannot be separated from the cooperation of the operation team, including that which occurs between the surgeon and assistant, and between the operation nurse and anesthesiologist. The operation team members should be a fixed unit, and cooperation among members should be standardized and orderly, leading to a tacit understanding.

Operation nurses who master the anatomy of pancreaticoduodenal surgery, the operation steps, and the surgeon's preferences and habits can effectively shorten the operation time. In order to achieve this goal, we have changed the traditional training model and adopted the method of cooperation training to train nurses in professional theory and skills (9). We have improved the comprehensive practical ability of surgical nurses by adopting the management mode of specialized rotation and specialized work (10). In consideration of the complex of the anatomy for pancreatic surgery, along with the characteristics and habits of different surgeons (11), we have configured a surgeon's preference card and a special consumables box for the operation, in which all types of commonly used items can be placed, such as vascular suture, vascular sling, hemostatic material, etc. In this study, the operation time and surgeon satisfaction of the patients in the experimental group were significantly better than those in the control group, which fully demonstrated the effectiveness of the nursing program in LPD.

Skilled nursing cooperation is of great significance in programmed LPD surgery. Though adequate preoperative preparation, nurses can master surgical procedures skillfully, keep their mind in sync with the surgeon, so that the operation can be carried out more smoothly and more efficiently.

In the future, we will continue to pay more attention on the accelerated rehabilitation surgery nursing strategy for LPD.

\section{Acknowledgments}

Funding: This work was supported by the National Natural Science Foundation of China (No. 81802419).

\section{Footnote}

Reporting Checklist: The authors have completed the STROBE reporting checklist. Available at http://dx.doi. org/10.21037/gs-20-726

Data Sharing Statement: Available at http://dx. doi. org/10. 21037/gs-20-726

Conflicts of Interest: All authors have completed the ICMJE uniform disclosure form (available at http://dx. doi. org/10.21037/gs-20-726). The authors have no conflicts of interest to declare.

Ethical Statement: The authors are accountable for all aspects of the work in ensuring that questions related to the accuracy or integrity of any part of the work are appropriately investigated and resolved. All procedures performed in this study involving human participants were in accordance with the Declaration of Helsinki (as revised in 2013). Individual consent for this retrospective analysis was waived. This study was also approved by Medical Ethics Committee of Sun Yat-sen Memorial Hospital, Sun Yat-sen University (No. SYSEC-KY-KS-2020-144).

Open Access Statement: This is an Open Access article distributed in accordance with the Creative Commons Attribution-NonCommercial-NoDerivs 4.0 International License (CC BY-NC-ND 4.0), which permits the noncommercial replication and distribution of the article with 
the strict proviso that no changes or edits are made and the original work is properly cited (including links to both the formal publication through the relevant DOI and the license). See: https://creativecommons.org/licenses/by-nc-nd/4.0/.

\section{References}

1. Gagner M, Pomp A. Laparoscopic pylorus-preserving pancreatoduodenectomy. Surg Endosc 1994;8:408-10.

2. Cai Y, Li Y, Gao P, et al. Laparoscopic pancreaticoduodenectomy with major venous resection and reconstruction with repassed round ligament: a case report. Ann Transl Med 2018;6:213.

3. Cai $Y$, Wang J, Wang X, et al. It is feasible to perform laparoscopic pancreaticoduodenectomy for patients with prior abdominal operation. Transl Cancer Res 2018;7:645-60.

4. Chen K, Zhou Y, Jin W, et al. Laparoscopic pancreaticoduodenectomy versus open pancreaticoduodenectomy for pancreatic ductal adenocarcinoma: oncologic outcomes and long-term survival. Surg Endosc 2020;34:1948-58.

5. Wang X, Cai Y, Jiang J, et al. Laparoscopic Pancreaticoduodenectomy: Outcomes and Experience of 550 Patients in a Single Institution. Ann Surg Oncol 2020.

Cite this article as: Qiu Y, Ouyang X, Luo M, Feng L, Zheng C, Li G. Application of a surgical nursing cooperation program in laparoscopic pancreaticoduodenectomy. Gland Surg 2020;9(5):1530-1534. doi: 10.21037/gs-20-726
[Epub ahead of print].

6. Zhang W, Wang K, Liu S, et al. A single-center clinical study of hepatic artery variations in laparoscopic pancreaticoduodenectomy: A retrospective analysis of data from 218 cases. Medicine (Baltimore) 2020;99:e20403.

7. Vining CC, Kuchta K, Schuitevoerder D, et al. Risk factors for complications in patients undergoing pancreaticoduodenectomy: A NSQIP analysis with propensity score matching. J Surg Oncol 2020;122:183-94.

8. Choi M, Hwang HK, Lee WJ, et al. Total laparoscopic pancreaticoduodenectomy in patients with periampullary tumors: a learning curve analysis. Surg Endosc 2020. [Epub ahead of print].

9. Pan L, Tan S, Liang A. Application of cooperative medical training method to improve the practical ability of orthopedic nurses. Chinese Journal of Nursing 2014;2:193-6.

10. Robertson JM, Dias RD, Yule S, et al. Operating Room Team Training with Simulation: A Systematic Review. J Laparoendosc Adv Surg Tech A 2017;27:475-80.

11. Nakagawa Y, Fukami Y, Harada T, et al. Laparoscopic pancreaticoduodenectomy for remnant pancreatic recurrence after laparoscopic distal pancreatectomy and hepatectomy for greater omentum leiomyosarcoma. Asian J Endosc Surg 2020;13:117-20. 